\title{
Strengthening the links between planning and health in England
}

\author{
Gemma McKinnon and colleagues argue that multidisciplinary action in planning and health will \\ contribute to more equitable communities and improved health and wellbeing
}

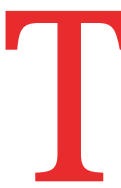

he importance of the environment in human health and wellbeing has been known for centuries. ${ }^{1}$ The fields of public health, environmental health, and town planning emerged mid-way through the 1800s when John Snow, an English physician, linked a cholera outbreak in London to the contaminated Broad Street public water pump, ${ }^{2}$ and British sanitarians, Edwin Chadwick and Benjamin Ward-Richardson, connected poor health with poor social and physical environments, inspiring Ebenezer Howard's garden cities movement. ${ }^{3}$ Despite our long history of understanding the detrimental effects on health of factors such as pollution and household overcrowding, modern regulatory and governance systems still permit development of the environment in ways that are likely to harm health. For example, throughout the 20th and 21st centuries as we have continued to urbanise, car-centric

\section{REY MESSAGES}

- The connection between the environment and health has been well known for centuries, yet modern regulatory and governance systems still permit the environment to be developed in ways that are likely to harm health

- Overlooking the importance of our environment threatens not only the health and wellbeing of communities across England, but the delivery of health services and the sustainability of our planet

- Shared leadership across the disciplines of planning and health needs to be established at the earliest stages of development to ensure places are designed using evidence based planning principles that reflect local health needs

- Healthcare professionals, practitioners, and academics must strive to maximise the opportunities we have through the planning process to support the long term health of the population and planet design has taken precedence over people centred design. ${ }^{4}$ As a result, non-communicable diseases, such as respiratory conditions, dementia, and some cancers, have become more prevalent.

A range of factors has contributed to the lack of attention given to the links between planning and health. These factors include a focus on infrastructure and housing provision to the detriment of broader community and health outcomes. Linked to this are the competing priorities within the National Planning Policy Framework, ${ }^{6}$ which underpin local town planning decision making in England. Here we make the case for examining the links between public health and planning. We point out that the built environment not only has direct and indirect consequences for the health and wellbeing of communities across England, but also for the delivery of health services, and indeed, the sustainability of our planet. ${ }^{7}$ ${ }^{8}$ As practitioners and academics working in planning and health, we argue that it is time to refocus on the foundation of good health and sustainability-the environment in which we live.

Association between environment and health Over the past decade evidence of the environmental effects on health and wellbeing has grown substantially. ${ }^{9}$ Organisations such as Public Health England and the National Institute for Health and Care Excellence (NICE) have combined key findings to support the built environment and public health professionals with policy and decision making. ${ }^{10}$ Figure 1 shows how modifications made to the design of the built environment can support improvements in health and reduce the risk of developing certain diseases, and also help to improve people's physical and mental wellbeing. Housing, as a key part of the built environment and health, is discussed in greater detail in box 1 . Similar resources advocating healthy spatial planning have also been developed by national bodies, such as NHS England, ${ }^{11}$ Sport England, ${ }^{12}$ and international bodies including the World Health
Organization, ${ }^{13}$ and the United Nations. ${ }^{14}$ It is important to understand, however, how these tools and frameworks can be used to support policy and decision making for the built environment.

In Essex, southeast England, public health and planning teams are encouraging the use of Sport England's 10 active design principles. ${ }^{15}$ The principles share common themes with Public Health England's 'design and planning principles' in figure 1. They promote opportunities to increase activity through walkable communities and by connecting walking and cycling routes, including ways to work collaboratively in the disciplines of health and planning to do so. Physical inactivity is responsible for one in six deaths across the United Kingdom, and despite the chief medical officer's recommendation of 150 minutes of moderate activity a week for adults aged 19-64, the population is becoming increasingly inactive. ${ }^{16}$ Physical inactivity disproportionately affects certain members of society-for example, those living in the most deprived areas are twice as likely to be physically inactive as those living in the least deprived neighbourhoods. ${ }^{17}$ Prioritising design that enables all people, regardless of socioeconomic status, age, or other characteristics, to be routinely active in their daily lives is therefore of vital importance for their health. Creating walkable neighbourhoods could also reduce reliance on cars, promoting health through the reduction of harmful pollutants.

\section{Strengthening our health provisions}

This type of principle based approach to planning for health is fast becoming a major focus for public health professionals across the country. The transfer of public health services from the NHS back to local government in 2012 provided a way for reuniting the two disciplines of health and planning, and encouraged the coproduction of policies in local development planning to deal with lifetime inequalities in health. ${ }^{23}$ Statutory local plans set out a vision for development over a period of 20 years and provide 


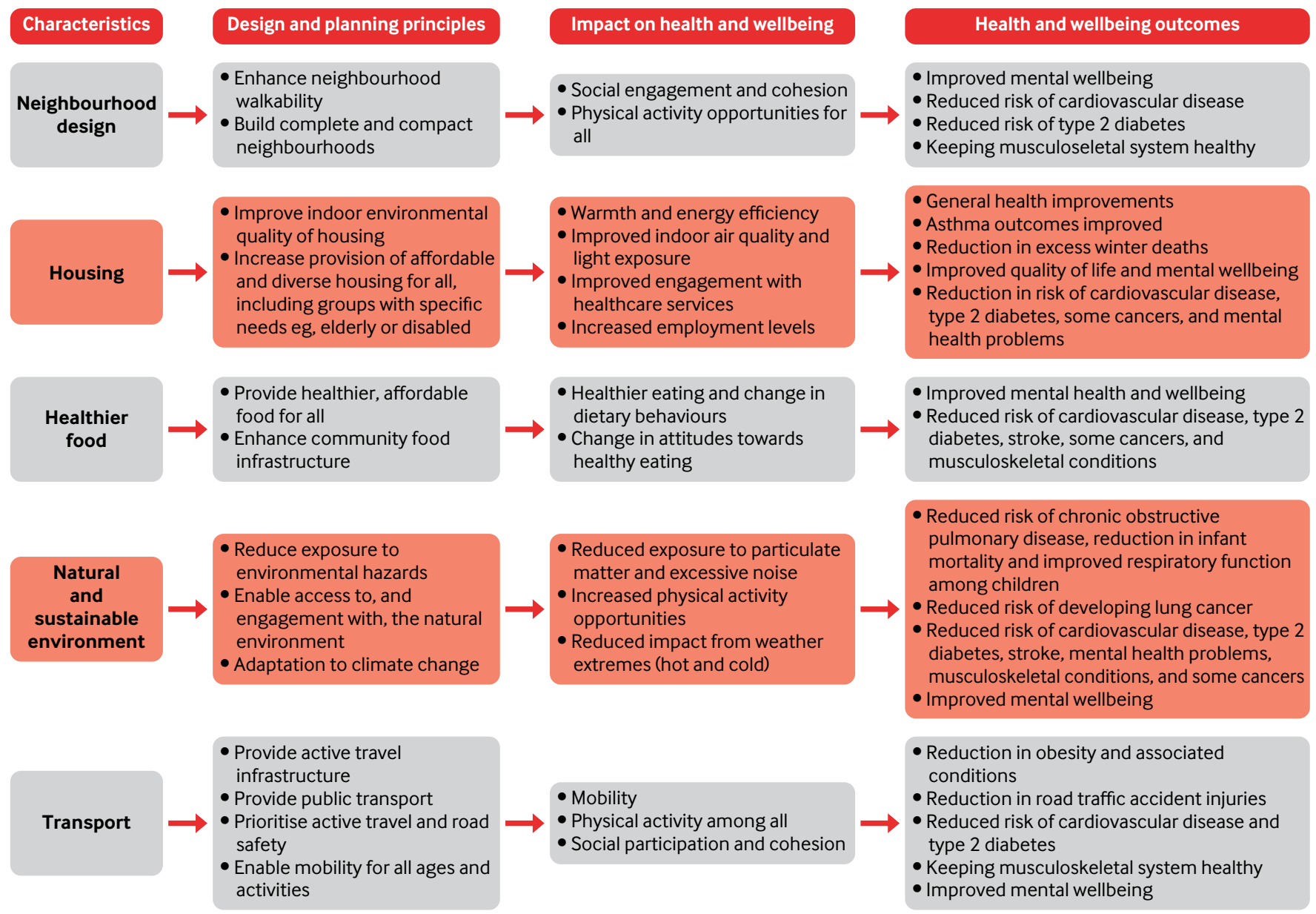

Fig 1 | Associations between design and planning principles and health and wellbeing (adapted from Public Health England's Spatial Planning for Health $)^{10}$

an opportunity for health practitioners to ensure that the promotion of health and wellbeing is embedded within local plans from the outset. A recent review of progress made in cooperation between planning and health by the Town and Country Planning Association found that most local planning policies make explicit links to health and wellbeing in transport, open space and recreation, and design policies. ${ }^{24}$

The review by the Town and Country Planning Association also found that despite national policy requirements set out in the National Planning Policy Framework, local plans were weak in their consideration of statutory local health strategies and assessment of health needs. ${ }^{23} \mathrm{~A}$ recent study shows that local authority teams face considerable challenges in translating research and evidence into practice owing to the complex political, economic, social, and multidisciplinary conditions under which they operate. ${ }^{25}$ Furthermore, as health professionals we must be better at providing and supporting the use of local health data to inform local planning and person centred design. Some examples of good practice exist, however, from which we can learn. In Warwickshire, central England, a place based approach to the assessment of joint strategic needs was undertaken and assessments of needs were carried out for localities of 30000 50000 people, loosely aligned to primary care networks. The public health data and recommendations from this two year programme are being used in spatial planning across Warwickshire. ${ }^{26}$

\section{Window of opportunity}

We are in the middle of a climate emergency that is affecting our health and prospects. ${ }^{27}$ Nations are working towards achieving the sustainable development goals. In England, the recent consultation on the government's prevention green paper Advancing our health: prevention in the 2020 s sets out the need for a fundamental change from a more curative approach to one of prevention and promoting the conditions for good health. ${ }^{28}$ We must take advantage of this suitable moment and act to further strengthen the links between planning and health to enable more healthy, equitable, and sustainable communities.

Aligning with the green paper, the NHS long term plan sets out the ambitions of the health service over the next 10 years, including its response to systems challenges-funding, workforce, increasing inequalities, and demand from a growing and ageing population. ${ }^{29}$ The long term plan states that the NHS has a wider role in influencing the shape of local communities, especially through its Healthy New Towns programme. ${ }^{11} \mathrm{~A}$ recent publication from the programme, Putting health into place, advocates that health professionals become more involved in the planning and development of new places. ${ }^{11}$ The publication points towards the need to establish shared leadership, linking planning and health at the earliest stages of developments. It also recommends the development of integrated care systemsthat is, partnerships between NHS organisations, local councils, and other 


\section{Box 1: Relation between housing and health}

In the UK people spend over $95 \%$ of their time indoors and $66 \%$ of this time in their homes. ${ }^{18}$ More vulnerable members of society (such as the young, the elderly, and those with a long term health condition) might spend up to $100 \%$ of their time indoors. ${ }^{19}$ Evidence suggests that poorly designed homes can exacerbate chronic conditions and increase the risk of injury. ${ }^{20}$ Affordable and quality housing for all is therefore critical for reducing inequalities in health and improving population health and wellbeing. Housing design standards such as Lifetime Homes can improve quality of life and help people to live in their homes for longer. ${ }^{21}$ Healthcare professionals are also well positioned to raise awareness about housing services among patients with concerns. For example, the UK government's affordable warmth scheme helps those living in private and social housing to make energy saving improvements to their homes. ${ }^{22}$ Many local schemes provide insulation or boiler replacement/repair services specifically for people with conditions exacerbated by excess cold, such as asthma and chronic obstructive pulmonary disease. ${ }^{23}$

Housing conditions also have a pivotal role in improving planetary health and in contributing to achieving a number of the sustainable development goals. As extreme weather, related to climate change, proceeds, it is important that housing is designed appropriately to cope with extremes in cold and heat. ${ }^{20}$ The World Health Organization's housing and health guidelines recommend that consideration should be given to thermal insulation, house orientation and ventilation, and heat supply. ${ }^{20}$

Note: Although our focus is on the English planning system, owing to the limited availability of housing data for England alone, data for the United Kingdom have been included.

partners, for managing operational and financial performance of services in their area and provides a framework for when these partnerships should be formed. The aim is to ensure a shared vision and a joined-up approach among stakeholders and across disciplines that is based on evidence about local health needs and environmental design.

\section{Conclusion}

This article does not suggest that the healthy planning and design of the built environment is in any way a "quick fix" for improved health and wellbeing in England. We recognise there are other social determinants, such as ethnicity, income, and gender, that affect population health. These elements must also be dealt with within and outside the planning system. ${ }^{30}$ In addition, planning itself can be a slow process. Nevertheless, we must maximise the opportunities we have to support long term health of the population and the planet. As a starting point to action we propose that

- $\quad$ Built environments are designed and developed using guidance from quality assured sources such as Public Health England and the Town and Country Planning Association

- $\quad$ Person centred design is favoured over an infrastructure led plan to ensure places support healthy, active communities

- $\quad$ The approach to person centred design is strengthened by ensuring that local health needs are linked to the plan- ning policy process, led by integrated care systems

- A stronger focus is placed on prevention and promoting the conditions for good health within all built environment plans, designs, and developments.

As healthcare professionals and practitioners working in the environmental determinants of health we must strive to use evidence based principles to advance health, or risk worsening health conditions, and deepening inequalities for patients and communities. It will be important to take advantage of existing and new networks to provide multidisciplinary action, both for the planning and design of the built environment and in support of more healthy, equitable, and thriving communities.

Contributors and sources: All authors conceived the idea for the article after a Salzburg global seminar on Building healthy, equitable communities: the role of inclusive urban development and investment conference. All authors contributed substantially to the conception of the work and the analysis of policy in England. GM led on editing, drafting, and revising of the content; $H P$ and $L T-G$ revised the final version critically. GM, LLT-G, and AJ wrote the three case studies in the article. HP and GM wrote the introduction. MC added the policy elements. All authors approved the final version and agree to be accountable for all aspects of the work.

Competing interests: We have read and understood BMJ policy on declaration of interests and have no relevant interests to declare.

Provenance and peer review: Commissioned; externally peer reviewed.

This article is part of a series from the Salzburg Global Seminar on building healthy equitable communities: the role of inclusive urban

development and investment. Open access fees were funded by the Robert Wood Johnson Foundation. The $B M /$ peer reviewed, edited, and made the decision to publish the article with no involvement from the foundation.

Gemma McKinnon, public health principal ${ }^{1,2}$

Helen Pineo, lecturer in sustainable and healthy built environments

Michael Chang, programme manager-healthy places $^{2,4,5}$

Laura Taylor-Green, head of wellbeing and public health $^{6}$

Annalise Johns Strategy, adviser ${ }^{7}$

Rachel Toms, programme manager-housing and health

${ }^{1}$ Warwickshire County Council, Warwick, UK

${ }^{2}$ Health and Wellbeing in Planning Network, London, UK

${ }^{3}$ University College London, London, UK

${ }^{4}$ World Health Organization Collaborating Centre for Healthy Urban Environments, Bristol, UK

${ }^{5}$ Public Health England, London UK

${ }^{6}$ Essex County Council, Essex UK

7 NHS England, London UK

Correspondence to: G McKinnon gem.mckinnon6@gmail.com

\section{(9) (1) O OPEN ACCESS}

This is an Open Access article distributed in accordance with the Creative Commons Attribution Non Commercial (CC BY-NC 4.0) license, which permits others to distribute, remix, adapt, build upon this work non-commercially, and license their derivative works on different terms, provided the original work is properly cited and the use is non-commercial. See: http://creativecommons.org/ licenses/by-nc/4.0/.

\section{D) Check for updates}

1 Barton H. City of well-being: a radical guide to planning. Routledge. Taylor \& Francis Group, 2017.

2 Brody H, Rip MR, Vinten-Johansen P, Paneth N, Rachman S. Map-making and myth-making in Broad Street: the London cholera epidemic, 1854 Lancet 2000;356:64-8. doi:10.1016/S01406736(00)02442-9

3 Hancock T, Duhl LJ. Healthy cities: promoting health in the urban context. World Health Organization Regional Office for Europe, 1986.

4 Frumkin H. Urban sprawl and public health: designing, planning, and building for healthy communities. Island Press, 2004.

5 Goryakin Y, Rocco L, Suhrcke M. The contribution of urbanization to non-communicable diseases: evidence from 173 countries from 1980 to 2008. Econ Hum Biol 2017;26:151-63. doi:10.1016/j. ehb.2017.03.004

6 Ministry of Housing. Communities and local government. National Planning Policy Framework. London: Ministry of Housing, Communities and Local Government; 2019. https://assets.publishing.service. gov.uk/government/uploads/system/uploads/ attachment_data/file/810197/NPPF_Feb_2019 revised.pdf

7 Reed S, Gopfert A, Wood S, Allwood D, Warburton W. Building healthier communities: the role of the NHS as an anchor institution. Health Foundation, 2019. https://www.health.org.uk/sites/default/ files/upload/publications/2019/102_Building\%20 healthier\%20communities_WEB.pdf 
8 Whitmee S, Haines A, Beyrer C, et al. Safeguarding human health in the Anthropocene epoch: report of The Rockefeller Foundation-Lancet Commission on planetary health. Lancet 2015;386:1973-2028. doi:10.1016/S0140-6736(15)60901-1

9 Barton H, Thompson S, Grant M, Burgess S. The Routledge handbook of planning for health and well-being. Routledge, 2015. doi:10.4324/9781315728261

10 Public Health England. Spatial planning for health: evidence review. PHE publications, 2017.

11 NHS England. Healthy new towns. England.nhs. uk. 2019. https://www.england.nhs.uk/ourwork/ innovation/healthy-new-towns/

12 Sport England. Active design: planning for health and wellbeing through sport and physical activity. Sport England, 2015. https://sportengland-productionfiles.s3.eu-west-2.amazonaws.com/s3fs-public/ spe003-active-design-published-october-2015email-2.pdf

13 World Health Organization What is a healthy city? Euro.who.int. 2019. http://www.euro.who.int/en/ health-topics/environment-and-health/urbanhealth/who-european-healthy-cities-network/whatis-a-healthy-city

14 UN-Habitat. (2019). Expert Group Meeting "Implementing the international guidelines on urban and territorial planning for improved environment and well-being" and side event "innovative approaches to planning for health for all” synthesis report. Nairobi: UN-Habitat. https:// www.bovanetwork.org/sites/bova/files/content/ attachments/2019-11-20/Implementing\%20 the\%20International\%20Guidelines\%20on\%20 Urban\%20and\%20Territorial\%20Planning\%20 for $\% 201$ mproved $\% 20$ Health\%20and\%20Wellbeing\%20-\%20Synthesis\%20report.pdf
15 Essex County Council. Essex Design Guide. 2018. https://www.essexdesignguide.co.uk/

16 Public Health England. 2019. Physical activity: applying All Our Health. https://www.gov.uk/ government/publications/physical-activity-applyingall-our-health/physical-activity-applying-all-our-health

17 Public Health England. 2014. Everybody active, every day. https://assets.publishing.service.gov.uk/ government/uploads/system/uploads/attachment_ data/file/374914/Framework_13.pdf

18 Schweizer C, Edwards RD, Bayer-Oglesby L, et al. Indoor time-microenvironment-activity patterns in seven regions of Europe. J Expo Sci Environ Epidemiol 2007;17:170-81. doi:10.1038/ sj.jes.7500490

19 Vardoulakis S, Dimitroulopoulou C, Thornes J, et al. Impact of climate change on the domestic indoor environment and associated health risks in the UK. Environ Int 2015;85:299-313. doi:10.1016/j. envint.2015.09.010

20 World Health Organization (WHO). WHO Housing and Health Guidelines. World Health Organization; 2018. https://apps.who.int/iris/bitstream/han dle/10665/276001/9789241550376-eng. pdf?ua $=1$

21 The Lifetime Homes Standard. Lifetimehomes.org. uk. 2010. http://www.lifetimehomes.org.uk/pages/ revised-design-criteria.html

22 Help from your energy supplier: the affordable warmth obligation. 2019. https://www.gov.uk/ energy-company-obligation

23 Carmichael L, Townshend TG, Fischer TB, et al. Urban planning as an enabler of urban health: challenges and good practice in England following the 2012 planning and public health reforms. Land Use Policy 2019;84:154-62. doi:10.1016/j. landusepol.2019.02.043
24 Chang M. 2019. The State of the Union: reuniting health with planning in promoting healthy communities. Town and Country Planning Association. https://www.tcpa.org.uk/the-state-ofthe-union-reuniting-health-with-planning-1

25 PHE. 2019, Spatial planning and health getting research into practice (GRIP): study report. https:// assets.publishing.service.gov.uk/government/ uploads/system/uploads/attachment_data/ file/842840/Spatial_Planning_and_Health.pdf

26 Warwickshire County Council. Health and wellbeing board agenda pack. Warwickshire County Council, 2020:37. https://democracy.warwickshire.gov.uk/ documents/g192/Public\%20reports\%20pack\%20 08th-Jan-2020\%2013.30\%20Health\%20and\%20 Wellbeing\%20Board.pdf?T=10

27 Watts N, Adger WN, Ayeb-Karlsson S, et al. The Lancet countdown: tracking progress on health and climate change. Lancet 2017;389:1151-64. doi:10.1016/ S0140-6736(16)32124-9

28 Department of Health and Social Care. Advancing our health: prevention in the 2020s - consultation document. London; 2019. https://www.gov.uk/ government/consultations/advancing-our-healthprevention-in-the-2020s/advancing-our-healthprevention-in-the-2020s-consultation-document

29 NHS England. The NHS long term plan. London: NHS England; 2019. https://www.longtermplan.nhs.uk/

30 Public Health England. Chapter 6: Social determinants of health. London: Public Health England; 2017. https://www.gov.uk/government/ publications/health-profile-for-england/chapter-6social-determinants-of-health

Cite this as: $B M / 2020 ; 369: \mathrm{m} 795$

http://dx.doi.org/10.1136/bmj.m795 